\title{
REVIEW
}

\section{Quality of life issues in men undergoing androgen deprivation therapy: a review}

\author{
Rowan G Casey, Niall M Corcoran and S Larry Goldenberg
}

Androgen deprivation therapy (ADT) has been an essential treatment option for treating prostate cancer (PCa). The role for hormonal treatment initially was restricted to men with metastatic and inoperable, locally advanced disease. Now it has been extended to neoadjuvant or adjuvant therapy for surgery and radiotherapy, for biochemical relapse after surgery or radiation, and even as primary therapy for non-metastatic disease. Fifty percent of PCa patients treated will receive ADT at some point. There is growing concern about the adverse effects and costs associated with more widespread ADT use. The adverse effects on quality of life (QoL), including physical, social and psychological well-being when men are androgen-deprived, may be considerable. This review examines the $Q$ oL issues in the following areas: body feminisation, sexual changes, relationship changes, cognitive and affective symptoms, fatigue, sleep disturbance, depression and physical effects. Further suggestions for therapeutic approaches to reduce these alterations are suggested.

Asian Journal of Andrology (2012) 14, 226-231; doi:10.1038/aja.2011.108; published online 9 January 2012

Keywords: androgen deprivation therapy; men; prostate cancer; quality of life

\section{INTRODUCTION}

Since the Nobel prize winning discovery of the androgen-sensitive nature of prostate cancer ( $\mathrm{PCa}$ ) cells, androgen deprivation has been a standard protocol for treating PCa. ${ }^{1}$ Initially, the role for hormonal treatment was restricted to men with metastatic and inoperable, locally advanced disease, but given the increase in prostate-specific antigen (PSA) testing, due to the recent PSA screening trials, ${ }^{2-4}$ there has been a huge increase in the number of PCa cases detected. This earlier detection and downward stage migration has been accompanied by a proliferation of treatment alternatives, including its use as neoadjuvant or adjuvant therapy for surgery and radiotherapy, for biochemical relapse after surgery or radiation, and even as primary therapy for non-metastatic disease. ${ }^{5}$ It appears now that patients are given androgen deprivation therapy (ADT) based on their PSA and not necessarily the presence of clinical symptoms, and they are likely to be on ADT for longer periods than in the past. The expansion of ADT has been most dramatic with external beam radiotherapy, i.e., from $9.8 \%$ to $74.6 \% .{ }^{5}$ In addition, the use of long-term neoadjuvant ADT (up to 3 years in combination with radiation therapy for highrisk PCa) will result in permanent castration to some men. Overall, it has been estimated that approximately $50 \%$ of PCa patients treated in industrialized nations will receive ADT at some point in their disease course. ${ }^{6}$

As a result of the increased diagnosis of $\mathrm{PCa}$, bilateral orchidectomy and oestrogen, once the main forms of ADT, have become superseded by ADT. ${ }^{7}$ New agents continue to be developed to increase the effectiveness of ADT including drugs that more effectively inhibit testosterone synthesis and others that block androgen receptor activation. ${ }^{8}$
Documented adverse effects of ADT include hot flashes/flushes, loss of libido, sexual dysfunction, gynaecomastia, decrease in bone mineral density with potential increased risk of fractures ${ }^{9}$ and increase in fat mass plus loss of lean muscle mass. ${ }^{10}$

ADT is also associated with metabolic syndrome (increased cholesterol, triglycerides and insulin resistance), diabetes and, possibly myocardial infarction and sudden cardiac death. ${ }^{11}$ It has also recently been reported that men with a previous history of myocardial infarction or congestive heart disease who undergo brachytherapy-based radiation treatment, may be harmed by ADT in terms of all-cause mortality. ${ }^{12}$

There is growing concern about the costs and adverse effects associated with more widespread ADT use, especially in older males who are more likely to have significant comorbidities. Thus, it is timely to review the adverse effects on quality of life (QoL), including physical, social and psychological well-being when men are subjected to androgen withdrawal (Table 1).

\section{QOL ISSUES}

Fossa et al. ${ }^{13}$ and Herr ${ }^{14}$ first described the adverse QoL features that are associated with ADT. Effects of ADT on cognitive function, ${ }^{15}$ anaemia, ${ }^{16}$ bone density and fractures ${ }^{17}$ were reported in the early 1990s. Further effects on QoL issue such as loss of muscle strength, ${ }^{18}$ diabetes and cardiovascular disease $\mathrm{e}^{19}$ appeared later in the literature.

Castrate levels of testosterone are associated with numerous physiological side effects that together form a constellation of symptoms now recognized as androgen deprivation syndrome. ${ }^{20}$ This syndrome is manifested in physical, social and sexual functional changes that have dramatic impact on overall and site specific QoL. The side effects of 
Table 1 ADT regimens come in a variety of combinations depending on the clinical and patient parameters

\begin{tabular}{ll}
\hline Medical & Surgical \\
\hline LHRHa monotherapy & Bilateral subcapsular orchidectomy \\
CAB (LHRHa+AA) & CAB (orchidectomy plus AA) \\
Intermittent androgen suppression & \\
AA monotherapy & \\
Newer therapies $^{\text {a }}$ & \\
\hline
\end{tabular}

Abbreviation: $A A$, anti-androgen; $A D T$, androgen deprivation therapy; $C A B$, combined androgen blockade; LHRHa, luteinizing hormone-releasing hormone agonist.

${ }^{a}$ Newer therapies include: LHRH antagonists-phase III clinical trial; ${ }^{95}$ oestrogens (diethylstilbestrol and parenteral oestrogen): PATCH study (MRC PR09)—phase II multicentre trial—ongoing. ${ }^{96}$

ADT also significantly affect the intimate partners of patients, who often experience more distress than the patients themselves. This has been confirmed in two studies including a recent meta-analysis. ${ }^{21,22}$

In this review, these QoL issues are adapted from a Canadian ADT survivorship working group ${ }^{23}$ and categorized into the following six areas:

- body feminisation;

- sexual changes;

- relationship changes;

- cognitive and affective symptoms;

- fatigue, sleep disturbance, depression;

- physical effects (added by authors).

\section{Body feminisation}

ADT changes oneself (Figure 1), in ways that may alter body image and can distress those who strongly associate male morphology with male identity. Gynaecomastia is particularly problematic. ${ }^{24,25}$ Some individuals are less bothered and able to adapt to, or ignore, or in some cases even autoeroticize these feminisation changes. ${ }^{26}$ However, most men tend to deal with gynaecomastia by hiding it and this can lead to social isolation. ${ }^{27}$

Gynaecomastia may be prevented to some degree by pre-treatment radiation. Treatment options include mastectomy or liposuction. ${ }^{28,29}$ Tamoxifen is effective for treating bicalutamide-induced gynaecomastia; ${ }^{30}$ however, it augments the oestrogen deficiency which is the primary cause of many side effects of androgen deprivation.

Other changes that can impact on masculine identity include weight gain, altered fat distribution, decrease in muscle mass, physical weakness, body hair loss, hot flashes and excess sweating. These can be socially embarrassing for patients, as they are most commonly associated with menopausal women.

Men also report that their genital size and sexual function are altered and that 'maleness is lost' after ADT. ${ }^{31}$ The loss of testicular volume and penile length related to ADT, radiation or surgery ${ }^{32,33}$ can

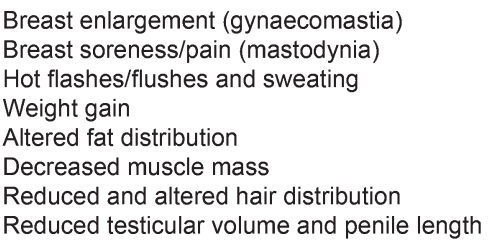

Figure 1 Features of body feminisation. erode a man's sense of his maleness and sexual self-esteem. Increased abdominal girth and thickening of pre-penile fat pad can further reduce visibility of the penis. It has been suggested by an expert working group ${ }^{23}$ that this inability to see the penis results in many ADT patients electing to sit while voiding, thus further diminishing their sense of masculinity. Penile length and girth can be maintained to some degree by penile rehabilitation methods to encourage erections, which, in turn, increase tissue oxygenation, cavernosal circulation and thus a normalized elastin/fibrinogen ratio. Standard penile rehabilitation techniques such as intracavernosal injections, vacuum therapy or the regular use of phosphodiesterase 5 inhibitors have been employed to counter these effects. ${ }^{34}$ However, the effectiveness of these treatments has not been rigorously assessed for patients on ADT and evidence suggests that phosphodiesterase 5 inhibitors work poorly in low-testosterone environments. ${ }^{35}$ Doctors and healthcare professionals should be aware of this in counselling patients.

\section{Sexual changes}

Approximately $85 \%$ of men who are started on ADT experience a number of sexual side effects (Figure 2) of which loss of erections is the single most troublesome ${ }^{36}$ in patients who have curative therapy for PCa and the literature demonstrates that both patients and partners are affected negatively by ED. ${ }^{37,38}$ Improving QoL can be achieved by improvements in ED which in turn improve sense of masculinity and self-esteem. ${ }^{39,40}$ Some patients report being especially distressed by a decrease in sexual thoughts and their response to visual and tactile prompts. Despite this reduced libido, some men remain troubled by the loss of erections, ${ }^{41}$ while others are relieved that the loss of erections is associated with the loss of libido. ${ }^{42}$

The ADT survivorship group ${ }^{23}$ has recognized that patients' lack of preparation for such sexual changes results in regret, anger or depression. Patients care about this disconnection with libido, ED and reduced orgasmic ability due to its importance to sense of self, masculinity, QoL and loss of intimate relationships.

Despite their lack of libido, many men want a functional erection for the benefit of their partners ${ }^{38}$ and this should be encouraged, though patients often find it's difficult to discuss. ${ }^{43,44}$ Studies in men with ED from other aetiologies have shown that psychological distress increases with severity of $\mathrm{ED}^{45}$ and those men who respond to ED treatment report clinically significant improvements in QoL as do their partners. ${ }^{46}$ A simple return of morning erections in hypogonadal men treated with testosteronere placement therapy has shown significant improvements in self-confidence. ${ }^{47}$ Low serum testosterone levels also have a direct effect on penile function by causing venous leak in PCa patients ${ }^{48-51}$ and, men treated with radical prostatectomy without concomitant ADT report substantial changes in self-confidence, secondary to iatrogenic ED. ${ }^{52}$

Delayed or loss of orgasm is a common complaint among patients on ADT, as it is in many hypogonadal men, ${ }^{53}$ and men on ADT can experience both lower penile vibratory thresholds and decreasing penile sensitivity. ${ }^{54}$ If incontinence (climacturia) occurs with orgasm, this can even be more distressing for both partners and is underreported by patients. ${ }^{55}$

Reduced libido
Erectile dysfunction
Reduced ejaculate
Incontinence on orgasm (climacturia)
Reduced orgasm

Figure 2 Sexual changes on androgen deprivation therapy. 
In addition, primary $\mathrm{PCa}$ treatments (e.g., radical prostatectomy, external-beam radiation, brachytherapy) eliminate most, if not all, ejaculate. For non-surgical patients on ADT who can still attain orgasm, ejaculatory volume and fertility will continually diminish and eventually disappear. Very few patients are prepared for this and certainly the younger patients find this distressing, as a sign of 'loss of masculinity'.

Ideally, the potential impact on all aspects of sexual function needs to be assessed through forthright discussion between patients, their partners and their healthcare providers before starting ADT. Successful treatment of a patient who has difficulty attaining orgasm often requires experimentation and open-mindedness regarding the use of sexual aids, or penetrative aids to induce orgasm. ${ }^{31,56}$ Overall, there is a paucity of studies examining awareness and motivation for penile rehabilitation or non-erectile-dependent sexual practices for ADT patients.

\section{Physical health}

During a 2-year follow-up study of patients in the CaPSURE registry ${ }^{57}$ men in the primary ADT group experienced steady declines in all domains related to physical well-being, even when corrected for age, comorbid conditions and clinical presentation, Dacal et al. ${ }^{58}$ also reported that men receiving ADT had significantly poorer physical function and general health. However, after controlling for predictors of comorbidity and total testosterone, they concluded that these two factors, and not ADT, contributed to the observed difference in physical health. Patients with PCa who were receiving ADT experienced worse health-related QoL than those not receiving ADT, but duration of ADT was not a contributing factor. These findings have important clinical implications regarding the decision to treat PCa patients with ADT.

Alibhai et al. ${ }^{10}$ performed the first prospective longitudinal study with a relatively large study of 87 patients with non-metastatic $\mathrm{PCa}$ who were starting on ADT, and two matched control groups of 86 men each: one group with PCa but not on ADT, and one group of healthy controls without a diagnosis of PCa. Over the course of 1-year study, grip strength in the ADT group declined significantly by the 3-month mark and remained low for the remainder of the study. In contrast, healthy and PCa controls did not exhibit any decrease in grip strength. Similarly, in both PCa and healthy controls, scores significantly improved for the 6-min walk test, whereas scores for ADT users remained flat. Subjectively, self-reported physical function on SF-36 surveys declined in the ADT group but remained stable in the PCa and healthy control cohorts. Of the seven domains of QoL evaluated, significant declines were seen in the ADT group in physical function, role function, bodily pain, vitality and emotional function. These differences were observed within the first 3 months and scores remained depressed for the course of the study. To offset these untoward effects, the authors recommend initiating a physical exercise programme in all patients starting ADT. ${ }^{10}$

Exercise, which helps to maintain bone strength, muscle mass and normal weight for patients on ADT, can also reduce fatigue, leading to improvements in mood, motivation and sexual functioning. ${ }^{59}$ A systematic literature review found grade A evidence that regular exercise, especially group-based and including some resistance training, improved muscular strength, aerobic endurance and overall QoL, as well as reduced fatigue. ${ }^{60}$

However, in older men ( $>65$ years) and those on ADT, it has been shown that only resistance exercise improves body composition and muscular fitness. ${ }^{61}$

Despite this knowledge, many men do not engage in appropriate physical activity levels. Even in patients who have had lifestyle interventions and showed improvements in exercise behaviour, dietary fat intake, total energy intake, fatigue, aerobic exercise tolerance and muscle strength, the rate of attrition is nearly $50 \%$ at 6 months. ${ }^{62}$ The ENGAGE study, a clinician referral and exercise physiologist-led physical activity programme, has also been designed to examine this. The primary outcome will be the number of minutes of moderate and strenuous exercise engaged in per week and secondarily, the impact of this physical activity programme on the psychological well-being, QoL and objective physical functioning of PCa survivors. ${ }^{63}$

\section{Relationship changes}

Reduced libido can result in withdrawal of emotional and physical intimacy $^{22}$ and can lead to significant partner distress. ${ }^{64}$ In general, partners of PCa sufferers describe even more distress than the patients. ${ }^{65}$ It has been observed that partners often want to talk about the ADT-associated changes, while the patient wants to minimize the issues. While denial appears to be a common way to cope, it is detrimental to PCa patients in the long term. ${ }^{66}$ Conflicting coping methods may lead to isolation of either or both partner ${ }^{67,68}$ and the loss of hope of satisfying sexual encounters and subsequent loss of intimacy can be even more destructive than that of sex. ${ }^{22}$ Some partners may be less attracted to their partner, while he is on ADT or, alternately, partners may begin to doubt their own attractiveness. ${ }^{69}$

Couples who strive to remain sexually intimate must make a concerted effort to stay emotionally and physically connected in novel ways. ${ }^{69}$ Other couples may adapt by discovering pleasure in nonpenetrative sexual activities with or without orgasm, incorporating areas outside the genitals and scrotum as erogenous, and incorporating sexual aids. ${ }^{31}$ Some couples may find it beneficial to seek professional counselling to assist with this.

\section{Cognitive and affective symptoms}

The effect of therapy on cognitive function has been a pertinent topic recently, with terms like 'chemo fog' and 'chemo brain' now routinely used to describe the cognitive effects of systemic chemotherapy. ${ }^{70} \mathrm{PCa}$ patients on $\mathrm{ADT}$, especially older men often report experiencing emotional lability, including tearfulness, increased irritability, and anger. ${ }^{71}$ Hopelessness and discouragement can result from decreased physical and sexual ability, as well as from changes to intimate relationships. For some patients, ADT signifies a progression of PCa disease in which hopes of cure are diminished.

Alibhai et al., ${ }^{72}$ using the same cohorts as in their earlier study, attempted to determine whether ADT affected cognitive function. In their report, the authors presented a prospective matched cohort study to more conclusively answer this question. The patients were evaluated using 14 cognitive tests covering eight unique cognitive domains (immediate span of attention, processing speed, verbal fluency, visual-spatial ability, verbal learning and memory, visual learning and memory, executive functions of working memory and executive functions of cognitive flexibility). While no difference was detected at earlier time points, by 12 months, ADT patients had small but significantly lower scores in immediate span of attention, working memory and visual-spatial function than both control groups. The group felt, however, that these subtle changes required further follow-up. They similarly pointed out that these patients had few comorbidities, were well educated and had a mean age of 78 years-a group of patients that may not represent the general spread of ADT patients.

Not all studies have reported declines in executive functions, attention, verbal memory and visual-spatial abilities. ${ }^{73}$ Although 
there appear to be specific mechanisms for testosterone to directly impact cognition, it is possible that the side effects of androgen ablation therapy (e.g., hot flashes, fatigue and anaemia) may contribute indirectly to impaired cognition. Clearly, some findings have been inconsistent because of low sample size and inadequate controls. The most obvious example of this inconsistency occurred in the study by Joly et al., ${ }^{74}$ in which no cognitive decline was reported after ADT.

Although no specific treatment for decline in cognitive dysfunction has been found, it has been suggested that low oestradiol levels may be responsible for many of changes and therefore oestrogen replacement may be beneficial. ${ }^{73,75}$

\section{Fatigue, sleep disturbance and depression}

PCa patients commonly state that fatigue, insomnia and depression are the most troublesome side effects of ADT. ${ }^{76}$ Hot flashes have been specifically linked to insomnia and disrupted sleep patterns and have been shown to contribute to depression in the elderly patients on ADT. ${ }^{77}$ Medications and/or cognitive-behavioural therapy can be used for the treatment of sleep disturbances and the associated depression. ${ }^{78}$ Changes in mood, sleep patterns, hot flashes, emotional withdrawal and other QoL domains also affect partners. ${ }^{79}$ The ADT survivor groups noted that many couples stop sharing a bed when a patient commences ADT leading to isolation of the partners from each other. ${ }^{23}$

The linkage between depression and low levels of serum testosterone remains unclear, and indeed may be related to patient age and comorbidities as it is more common in men over age 65 years. ${ }^{80}$ Regardless of whether it is attributable to the treatment side effects or surgery or radiation ${ }^{81}$ or testosterone deficiency itself, patients do experienced expression as such appropriate treatment should begin as early as possible.

\section{INTERMITTENT ANDROGEN SUPPRESSION}

The use of intermittent rather than continuous androgen deprivation remains an important research topic within urology. Several studies in PCa cell lines and in mouse models suggest that intermittent androgen ablation delays the time to the development of hormone refractory disease. ${ }^{82,83}$ In human studies, QoL is improved on intermittent androgen ablation ${ }^{84}$ as many of the side effects of androgen deprivation can be avoided or reversed with the 'holiday' periods of intermittent therapy. For example, patients report improved sexual function, fewer hot flashes, and an improved sense of well-being. ${ }^{84}$ Furthermore, bone loss associated with ADT seems to slow or stop during the offtreatment periods. ${ }^{85}$

In two recent reports of international phase III trials, intermittent therapy was shown to be non-inferior to continuous therapy in men with PSA progression after radical therapy. ${ }^{86,87}$ Many, but not all intermittent patients showed significant improvements in global QoL. ${ }^{88} \mathrm{In}$ the near future, data from the other two major ongoing multicentre randomized, prospective studies (NCIC PR8 and SWOG 9346) will provide more information on the QoL benefits and the prevention of the long-term complications of intermittent androgen suppression versus continuous $\mathrm{ADT}$. If these trials also demonstrate non-inferiority, then patients who have metastatic PCa may have significant improvements, in both self and partner's QoL, on intermittent androgen deprivation without compromising long-term efficacy of therapy.

\section{CONCLUSION}

Almost one-half of all men treated for PCa will be offered ADT at some time during their treatment. As a consequence of improved PCa detection and treatment, patients are starting ADT earlier than before; and many are remaining on it longer, some for over a decade, even when they are otherwise free of cancer symptoms. For the rest of their lives, these patients and their partners will have to adapt to its side effects. Although ADT may delay the onset or reappearance of cancer symptoms, life without testosterone can be profoundly challenging.

Rather than simply providing patients with a list of potential side effects, clinicians should discuss with both patients and partners the anticipated effects and potential physical, psychological and social changes. Some treatments aimed at a specific symptom exacerbate other symptoms. For example, treatments for hot flashes with medroxyprogesterone acetate, which has been shown to have good efficacy in a recent double-blind, randomized trial, ${ }^{89}$ may negatively affect cognitive functions, ${ }^{90}$ and selective serotonin reuptake inhibitors, which have been found to be effective at reducing hot flashes, may further decrease libido and ability to orgasm..$^{91}$

It has been argued that the full biopsychosocial impact from ADT on the patient and partner is beyond the scope of urological expertise. However, ignoring the psychological impact of ADT on the partner compromises the health and welfare of the patients themselves. A recent study found that the psychological distress of the female partners predicts the ultimate health of male patients. ${ }^{92}$ Therefore, whenever possible, partners should be included in the treatment decision and consent process and provided adequate and appropriate support. ${ }^{93}$

A multidisciplinary 'survivorship' team approach should exist for the management of ADT patients and their partners. Such a programme, should probably be called an 'ADT management programme' since the word 'survivorship' is not always properly understood and may lead patients to think that they may not survive ADT. Any effective ADT management programme also needs to be pre-emptive and both patients and their partners need to be enrolled in it before, or at the initiation of, $\mathrm{ADT}$ in order to maximize benefits and compliance. It has been pointed out in a recent review of the Wassersug's paper ${ }^{94}$ that consultations with patients and their partners held jointly may misinform clinicians about the individual needs of patients and partners, simply because the couple may feel that they must present a united front in the presence of their healthcare providers. Effort should thus be made to interview patients and partners separately to help reveal their individual concerns.

Ideally, this discussion should include a clinical psychologist, relationship counsellor, sex therapist or sexual medicine specialist for complex sexual and relationship issues, nutritionist, exercise specialist, endocrinologist and urologist.

The Men's Health Initiative of British Columbia and the Vancouver Prostate Centre are currently seeking funding and working towards a PCa survivorship clinic model. The goal of the programme is to improve the QoL of PCa patients and their partners through a comprehensive and integrated biopsychosocial survivor's programme that starts at diagnosis and extends through decision-making, surveillance, active intervention, advanced disease, to end of life care.

This programme will identify and utilize appropriate experts and resources to motivate patient (and partner) self-care in many critical areas such as sexual and bladder function, nutrition, exercise and cardiovascular risk reduction. It should improve self-esteem and dyadic quality for both patients and their partners. It will require that all QoL issues be addressed, in a dedicated setting and have its efficacy be continually and rigorously assessed.

The programme will then encourage and promote positive physical, mental and spiritual health and early education to help cope with treatment sequelae. 


\section{AUTHOR CONTRIBUTIONS}

RGC wrote the article and revised it. NMC and SLG edited the draft and made important critical intellectual changes. All authors reviewed and edited the final version.

\section{COMPETING FINANCIAL INTERESTS}

All authors declare that there are no competing financial interests.

1 Huggins C, Hodges CV. Studies on prostatic cancer. I. The effect of castration, of estrogen and androgen injection on serum phosphatases in metastatic carcinoma of the prostate. CA Cancer J Clin 1972; 22: 232-40.

2 Schroder FH, Hugosson J, Roobol MJ, Tammela TL, Ciatto S et al. Screening and prostate-cancer mortality in a randomized European study. N Engl J Med 2009; 360: 1320-8.

3 Hugosson J, Carlsson S, Aus G, BergdahI S, Khatami A et al. Mortality results from the Goteborg randomised population-based prostate-cancer screening trial. Lancet Oncol 2010; 11: 725-32.

4 Andriole GL, Levin DL, Crawford ED, Gelmann EP, Pinsky PF et al. Prostate Cancer Screening in the Prostate, Lung, Colorectal and Ovarian (PLCO) Cancer Screening Trial: findings from the initial screening round of a randomized trial. J Nat/ Cancer Inst 2005; 97: 433-8.

5 Cooperberg MR, Grossfeld GD, Lubeck DP, Carroll PR. National practice patterns and time trends in androgen ablation for localized prostate cancer. J Natl Cancer Inst 2003; 95: 981-9.

6 Meng MV, Grossfeld GD, Sadetsky N, Mehta SS, Lubeck DP et al. Contemporary patterns of androgen deprivation therapy use for newly diagnosed prostate cancer. Urology 60: 2002; 7-11; discussion 11-2.

7 Shahinian VB, Kuo YF, Freeman JL, Goodwin JS. Risk of fracture after androgen deprivation for prostate cancer. N Engl J Med 2005; 352: 154-64.

8 Chen Y, Clegg NJ, Scher HI. Anti-androgens and androgen-depleting therapies in prostate cancer: new agents for an established target. Lancet Oncol 2009; 10: 981-91.

9 Herr HW, Kornblith AB, Ofman U. A comparison of the quality of life of patients with metastatic prostate cancer who received or did not receive hormonal therapy. Cancer 1993; 71: 1143-50.

10 Alibhai SM, Gogov S, Allibhai Z. Long-term side effects of androgen deprivation therapy in men with non-metastatic prostate cancer: a systematic literature review. Crit Rev Oncol Hematol 2006; 60: 201-15.

11 Saylor PJ, Smith MR. Metabolic complications of androgen deprivation therapy for prostate cancer. J Urol 2009; 181: 1998-2006; discussion 2007-8.

12 Nguyen PL, Chen MH, Beckman JA, Beard CJ, Martin NE et al. Influence of androgen deprivation therapy on all-cause mortality in men with high-risk prostate cancer and a history of congestive heart failure or myocardial infarction. Int J Radiat Oncol Biol Phys; e-pub ahead of print 25 June 2011; doi:10.1016/j.ijrobp.2011.04.067.

13 Fossa SD, Kaasa S, da Silva FC, Suciu S, Hengeveld MW. Quality of life in prostate cancer patients. Prostate Supp/ 1991; 4: 145-8.

14 Herr HW. Quality of life in prostate cancer patients. CA Cancer J Clin 1997; 47: 20717.

15 Newton C, Slota D, Yuzpe AA, Tummon IS. Memory complaints associated with the use of gonadotropin-releasing hormone agonists: a preliminary study. Fertil Steril 1996; 65: $1253-5$

16 Chen AC, Petrylak DP. Complications of androgen-deprivation therapy in men with prostate cancer. Curr Urol Rep 2005; 6: 210-6.

17 Diamond T, Campbell J, Bryant C, Lynch W. The effect of combined androgen blockade on bone turnover and bone mineral densities in men treated for prostate carcinoma: longitudinal evaluation and response to intermittent cyclic etidronate therapy. Cancer 1998; 83: 1561-6.

18 Basaria S, Lieb J 2nd, Tang AM, DeWeese T, Carducci M et al. Long-term effects of androgen deprivation therapy in prostate cancer patients. Clin Endocrinol (Oxf) 2002 ; 56: 779-86

19 Keating NL, O'Malley AJ, Freedland SJ, Smith MR. Diabetes and cardiovascular disease during androgen deprivation therapy: observational study of veterans with prostate cancer. J Natl Cancer Inst 2010; 102: 39-46.

20 Shahinian VB, Kuo YF, Freeman JL, Goodwin JS. Risk of the 'androgen deprivation syndrome' in men receiving androgen deprivation for prostate cancer. Arch Intern Med 2006; 166: 465-71.

21 Kornblith AB, Herr HW, Ofman US, Scher HI, Holland JC. Quality of life of patients with prostate cancer and their spouses. The value of a data base in clinical care. Cancer 1994; 73: 2791-802.

22 Hagedoorn M, Sanderman R, Bolks HN, Tuinstra J, Coyne JC. Distress in couples coping with cancer: a meta-analysis and critical review of role and gender effects. Psychol Bull 2008; 134: 1-30.

23 Elliott S, Latini DM, Walker LM, Wassersug R, Robinson JW. Androgen deprivation therapy for prostate cancer: recommendations to improve patient and partner quality of life. J Sex Med 2010; 7: 2996-3010.

24 Harrington JM, Jones EG, Badger T. Body image perceptions in men with prostate cancer. Oncol Nurs Forum 2009; 36: 167-72.
25 Harrington JM, Badger TA. Body image and quality of life in men with prostate cancer. Cancer Nurs 2009; 32: E1-7.

26 Wassersug RJ, Oliffe JL. The social context for psychological distress from iatrogenic gynecomastia with suggestions for its management. J Sex Med 2009; 6: 989-1000.

27 Navon L, Morag A. Advanced prostate cancer patients' ways of coping with the hormonal therapy's effect on body, sexuality, and spousal ties. Qual Health Res 2003; 13: 1378-92.

28 Sieber PR. Treatment of bicalutamide-induced breast events. Expert Rev Anticancer Ther 2007; 7: 1773-9.

29 Guise TA, Oefelein MG, Eastham JA, Cookson MS, Higano CS et al. Estrogenic side effects of androgen deprivation therapy. Rev Urol 2007; 9: 163-80.

30 Bedognetti D, Rubagotti A, Conti G, Francesca F, de Cobelli O et al. An open, randomised, multicentre, phase 3 trial comparing the efficacy of two tamoxifen schedules in preventing gynaecomastia induced by bicalutamide monotherapy in prostate cancer patients. Eur Urol 2010; 57: 238-45.

31 Wassersug RJ. Mastering emasculation. J Clin Oncol 2009; 27: 634-6.

32 Munding MD, Wessells HB, Dalkin BL. Pilot study of changes in stretched penile length 3 months after radical retropubic prostatectomy. Urology 2001; 58: 567-9.

33 Haliloglu A, Baltaci S, Yaman O. Penile length changes in men treated with androgen suppression plus radiation therapy for local or locally advanced prostate cancer. J Urol 2007; 177: 128-30.

34 Muller A, Parker M, Waters BW, Flanigan RC, Mulhall JP. Penile rehabilitation following radical prostatectomy: predicting success. J Sex Med 2009; 6: 2806-12.

35 DiBlasio CJ, Malcolm JB, Derweesh IH, Womack JH, Kincade MC et al. Patterns of sexual and erectile dysfunction and response to treatment in patients receiving androgen deprivation therapy for prostate cancer. BJU Int 2008; 102: 39-43.

36 Matthew AG, Goldman A, Trachtenberg J, Robinson J, Horsburgh S et al. Sexual dysfunction after radical prostatectomy: prevalence, treatments, restricted use of treatments and distress. J Urol 2005; 174: 2105-10.

37 Fisher WA, Eardley I, McCabe M, Sand M. Erectile dysfunction (ED) is a shared sexual concern of couples I: couple conceptions of ED. J Sex Med 2009; 6: 2746-60.

38 Fisher WA, Eardley I, McCabe M, Sand M. Erectile dysfunction (ED) is a shared sexual concern of couples II: association of female partner characteristics with male partner ED treatment seeking and phosphodiesterase type 5 inhibitor utilization. J Sex Med 2009; 6: 3111-24

39 Bokhour BG, Clark JA, Inui TS, Silliman RA, Talcott JA. Sexuality after treatment for early prostate cancer: exploring the meanings of "erectile dysfunction". J Gen Intern Med 2001; 16: 649-55.

40 Bokhour BG, Powel LL, Clark JA. No less a man: reconstructing identity after prostate cancer. Commun Med 2007; 4: 99-109.

41 Dahn JR, Penedo FJ, Gonzalez JS, Esquiabro M, Antoni MH et al. Sexual functioning and quality of life after prostate cancer treatment: considering sexual desire. Urology 2004; 63: 273-7.

42 Low WY, Ng CJ, Choo WY, Tan HM. How do men perceive erectile dysfunction and its treatment? A qualitative study on opinions of men. Aging Male 2006; 9: 175-80.

43 Burns SM, Mahalik JR. Sexual functioning as a moderator of the relationship between masculinity and men's adjustment following treatment for prostate cancer. Am J Mens Health 2008; 2: 6-16.

44 Latini DM, Penson DF, Wallace KL, Lubeck DP, Lue TF. Longitudinal differences in psychological outcomes for men with erectile dysfunction: results from ExCEED. J Sex Med 2006; 3: 1068-76.

45 Latini DM, Penson DF, Wallace KL, Lubeck DP, Lue TF. Clinical and psychosocial characteristics of men with erectile dysfunction: baseline data from ExCEED. J Sex Med 2006; 3: 1059-67.

46 Cayan S, Bozlu M, Canpolat B, Akbay E. The assessment of sexual functions in women with male partners complaining of erectile dysfunction: does treatment of male sexual dysfunction improve female partner's sexual functions? J Sex Marital Ther 2004; 30: 333-41.

47 Jockenhovel F, Minnemann T, Schubert M, Freude S, Hubler D et al. Timetable of effects of testosterone administration to hypogonadal men on variables of sex and mood. Aging Male 2009; 12: 113-8.

48 Traish A, Kim N. The physiological role of androgens in penile erection: regulation of corpus cavernosum structure and function. J Sex Med 2005; 2: 759-70.

49 Traish AM. Androgens play a pivotal role in maintaining penile tissue architecture and erection: a review. J Androl 2009; 30: 363-9.

50 Yassin AA, Saad F, Traish A. Testosterone undecanoate restores erectile function in a subset of patients with venous leakage: a series of case reports. J Sex Med 2006; 3: 727-35.

51 Dorff TB, Vogelzang NJ. Use of testosterone replacement therapy in patients with prostate cancer. Curr Urol Rep 2011; 12: 223-8.

52 Nelson CJ, Deveci S, Stasi J, Scardino PT, Mulhall JP. Sexual bother following radical prostatectomyjsm. J Sex Med 2010; 7: 129-35.

53 Corona G, Jannini EA, Lotti F, Boddi V, de Vita G et al. Premature and delayed ejaculation: two ends of a single continuum influenced by hormonal milieu. Int $J$ Androl 2011; 34: 41-8.

54 Rowland DL. Penile sensitivity in men: a composite of recent findings. Urology 1998; 52: 1101-5.

55 Choi JM, Nelson CJ, Stasi J, Mulhall JP. Orgasm associated incontinence (climacturia) following radical pelvic surgery: rates of occurrence and predictors. J Urol 2007; 177: 2223-6.

56 Gray RE, Klotz LH. Restoring sexual function in prostate cancer patients: an innovative approach. Can J Urol 2004; 11: 2285-9. 
57 Sadetsky N, Greene K, Cooperberg MR, Hubbard A, Carroll PR et al. Impact of androgen deprivation on physical well-being in patients with prostate cancer: analysis from the CaPSURE (Cancer of the Prostate Strategic Urologic Research Endeavor) registry. Cancer 2011; 117: 4406-13.

58 Dacal K, Sereika SM, Greenspan SL. Quality of life in prostate cancer patients taking androgen deprivation therapy. J Am Geriatr Soc 2006; 54: 85-90.

59 Newton RU, Taaffe DR, Spry N, Gardiner RA, Levin G et al. A phase III clinical trial of exercise modalities on treatment side-effects in men receiving therapy for prostate cancer. BMC Cancer 2009; 9: 210.

60 Keogh JW, Macleod RD. Body composition, physical fitness, functional performance, quality of life, and fatigue benefits of exercise for prostate cancer patients: a systematic review. J Pain Symptom Manage; e-pub ahead of print 1 Jun 2011; doi:10.1016/j.jpainsymman.2011.03.006.

61 Alberga AS, Segal RJ, Reid RD, Scott CG, Sigal RJ et al. Age and androgen-deprivation therapy on exercise outcomes in men with prostate cancer. Support Care Cancer e-pub ahead of print 3 May 2011; doi:10.1007/s00520-011-1169-x.

62 Bourke L, Doll H, Crank H, Daley A, Rosario D et al. Lifestyle intervention in men with advanced prostate cancer receiving androgen suppression therapy: a feasibility study. Cancer Epidemiol Biomarkers Prev 2011; 20: 647-57.

63 Livingston PM, Salmon J, Courneya KS, Gaskin CJ, Craike M et al. Efficacy of a referra and physical activity program for survivors of prostate cancer [ENGAGE]: rationale and design for a cluster randomised controlled trial. BMC Cancer 2011; 11: 237

64 Soloway CT, Soloway MS, Kim SS, Kava BR. Sexual, psychological and dyadic qualities of the prostate cancer 'couple'. BJU Int 2005; 95: 780-5.

65 Cliff AM, MacDonagh RP. Psychosocial morbidity in prostate cancer: II. A comparison of patients and partners. BJU Int 2000; 86: 834-9.

66 Roesch SC, Adams L, Hines A, Palmores A, Vyas P et al. Coping with prostate cancer: a meta-analytic review. J Behav Med 2005; 28: 281-93.

67 Ko CM, Malcarne VL, Varni JW, Roesch SC, Banthia R et al. Problem-solving and distress in prostate cancer patients and their spousal caregivers. Support Care Cancer 2005; 13: 367-74.

68 Navon L, Morag A. Advanced prostate cancer patients' relationships with their spouses following hormonal therapy. Eur J Oncol Nurs 2003; : 73-80; discussion 81-2.

69 Walker LM, Robinson JW. The unique needs of couples experiencing androgen deprivation therapy for prostate cancer. J Sex Marital Ther 2010; 36: 154-65.

70 Tadros NN, Garzotto M. Androgen deprivation therapy for prostate cancer: not so simple. Asian J Androl 2011; 13: 187-8.

$71 \mathrm{Ng} \mathrm{C}$, Kristjanson LJ, Medigovich K. Hormone ablation for the treatment of prostate cancer: the lived experience. Urol Nurs 2006; 26: 204-12; discussion 215-8.

72 Alibhai SM, Breunis H, Timilshina N, Marzouk S, Stewart D et al. Impact of androgendeprivation therapy on cognitive function in men with nonmetastatic prostate cancer. J Clin Oncol 2010; 28: 5030-7.

73 Nelson CJ, Lee JS, Gamboa MC, Roth AJ. Cognitive effects of hormone therapy in men with prostate cancer: a review. Cancer 2008; 113: 1097-106.

74 Joly F, Alibhai SM, Galica J, Park A, Yi QL et al. Impact of androgen deprivation therapy on physical and cognitive function, as well as quality of life of patients with nonmetastatic prostate cancer. J Urol 2006; 176: 2443-7.

75 Holzbeierlein JM, McLaughlin MD, Thrasher JB. Complications of androgen deprivation therapy for prostate cancer. Curr Opin Urol 2004; 14: 177-83.

76 Herr HW, O'Sullivan M. Quality of life of asymptomatic men with nonmetastatic prostate cancer on androgen deprivation therapy. J Urol 2000; 163: 1743-6.

77 Cherrier MM, Aubin S, Higano CS. Cognitive and mood changes in men undergoing intermittent combined androgen blockade for non-metastatic prostate cancer. Psychooncology 2009; 18: 237-47

78 Berger AM. Update on the state of the science: sleep-wake disturbances in adult patients with cancer. Oncol Nurs Forum 2009; 36: E165-77.
79 Sanda MG, Dunn RL, Michalski J, Sandler HM, Northouse L et al. Quality of life and satisfaction with outcome among prostate-cancer survivors. N Engl J Med 2008; 358 1250-61

80 Schmidt PJ, Berlin KL, Danaceau MA, Neeren A, Haq NA et al. The effects of pharmacologically induced hypogonadism on mood in healthy men. Arch Gen Psychiatry 2004; 61: 997-1004.

81 Hervouet S, Savard J, Simard S, Ivers H, Laverdiere J et al. Psychological functioning associated with prostate cancer: cross-sectional comparison of patients treated with radiotherapy, brachytherapy, or surgery. J Pain Symptom Manage 2005; 30: 474-84.

82 Akakura K, Bruchovsky N, Goldenberg SL, Rennie PS, Buckley AR et al. Effects of intermittent androgen suppression on androgen-dependent tumors. Apoptosis and serum prostate-specific antigen. Cancer 1993; 71: 2782-90.

83 Sato N, Gleave ME, Bruchovsky N, Rennie PS, Goldenberg SL et al. Intermittent androgen suppression delays progression to androgen-independent regulation of prostate-specific antigen gene in the LNCaP prostate tumour model. J Steroid Biochem Mol Biol 1996; 58: 139-46.

84 Grossfeld GD, Small EJ, Lubeck DP, Latini D, Broering JM et al. Androgen deprivation therapy for patients with clinically localized (stages T1 to T3) prostate cancer and for patients with biochemical recurrence after radical prostatectomy. Urology 2001; 58: 56-64.

85 Yu EY, Kuo K, Gulati R, Jiang PY, Higano CS. Dynamics of bone mineral density during intermittent androgen deprivation for men with biochemical recurrence of prostate cancer. J Clin Oncol 2010; 28: abstr 4558.

86 Crook JM, O'Callaghan CJ, Ding K, Duncan G, Dearnaley DP et al. A phase III randomized trial of intermittent vs. continuous androgen suppression for PSA progression after radical therapy (NCIC CTG PR.7/SWOG JPR 7/CTSU JPR.7/UK Intercontinental Trial CRUKE/01/013). J Clin Oncol 2011; 29: abstr 4514.

87 Calais da Silva FE, Bono AV, Whelan P, Brausi M, Marques Queimadelos A et al Intermittent androgen deprivation for locally advanced and metastatic prostate cancer: results from a randomised phase 3 study of the South European Uroncological Group. Eur Urol 2009; 55: 1269-77.

88 Duncan GG, O'Callaghan CJ, Ding K, Dearnaley DP, Higano CS. QOL/outcomes of an international phase 3 trial of intermittent vs continuous hormone therapy for relapsed prostate. In: Proceedings of the ESTRO Anniversary Congress, 2011 May 8-12; London, UK; 2011. p15.

89 Irani J, Salomon L, Oba $R$, Bouchard $P$, Mottet N. Efficacy of venlafaxine, medroxyprogesterone acetate, and cyproterone acetate for the treatment of vasomotor hot flushes in men taking gonadotropin-releasing hormone analogues for prostate cancer: a double-blind, randomised trial. Lancet Oncol 2010; 11: 147-54.

90 Maki PM, Sundermann E. Hormone therapy and cognitive function. Hum Reprod Update 2009; 15: 667-81.

91 Corona G, Ricca V, Bandini E, Mannucci E, Lotti F et al. Selective serotonin reuptake inhibitor-induced sexual dysfunction. J Sex Med 2009; 6: 1259-69.

92 Kim Y, Kashy DA, Wellisch DK, Spillers RL, Kaw CK et al. Quality of life of couples dealing with cancer: dyadic and individual adjustment among breast and prostate cancer survivors and their spousal caregivers. Ann Behav Med 2008; 35: 230-8.

93 Tombal B. A holistic approach to androgen deprivation therapy: treating the cance without hurting the patient. Urol Int 2009; 83: 373-8.

94 Wassersug R. Androgen deprivation therapy for prostate cancer: recommendations to improve patient and partner quality of life. Uro Today Berkeley, CA, Digital Science Press Inc.; 2010.

95 Klotz L, Boccon-Gibod L, Shore ND, Andreou C, Persson BE et al. The efficacy and safety of degarelix: a 12-month, comparative, randomized, open-label, parallel-group phase III study in patients with prostate cancer. BJU Int 2008; 102: 1531-8.

96 Langley RE, Godsland IF, Kynaston H, Clarke NW, Rosen SD et al. Early hormonal data from a multicentre phase II trial using transdermal oestrogen patches as first-line hormonal therapy in patients with locally advanced or metastatic prostate cancer. BJU Int 2008; 102: 442-5. 